\title{
Aggressive surgery based on an anatomical subclassification of craniopharyngiomas
}

\author{
Hiroki Morisako, MD, Takeo Goto, MD, Hiroyuki Goto, MD, Christian Aisse Bohoun, MD, \\ Samantha Tamrakar, MD, and Kenji Ohata, MD \\ Department of Neurosurgery, Osaka City University Graduate School of Medicine, Osaka, Japan
}

\begin{abstract}
OBJECTIVE Craniopharyngiomas remain a particularly formidable challenge in the neurosurgical field. Because these lesions involve the hypothalamus and ophthalmological systems, their resection is associated with either higher rates of mortality and recurrence or a lower rate of radical resection. The authors report the outcomes of aggressive surgeries based on an anatomical subclassification of craniopharyngiomas.
\end{abstract}

METHODS Clinical and ophthalmological examinations, imaging studies, endocrinological studies, neuropsychological function, and surgical complications in all patients who had undergone microsurgical resection for craniopharyngioma at Osaka City University hospital between January 2000 and December 2014 were retrospectively reviewed through the medical records. Radical resections were planned in all of the patients. To help choose the correct surgical approach, craniopharyngiomas were classified based on tumor origin. The 4 possible groups included the intrasellar type, prechiasmatic type, retrochiasmatic type, and intra-third ventricle type. A multistage surgery was planned in some cases.

RESULTS Seventy-two cases of craniopharyngioma were resected. Thirty-two patients (44.4\%) had undergone previous surgical procedures at other institutions. Thirty-five cases (48.6\%) were classified as retrochiasmatic, $19(26.4 \%)$ as prechiasmatic, $12(16.7 \%)$ as intra-third ventricle, and $6(8.3 \%)$ as intrasellar. In 26 cases (36.1\%), multistage surgery was required to complete the radical resection. Overall, 41 cases involved an orbitozygomatic approach; 21, a transpetrosal approach; 21, an interhemispheric approach; and 14, a transsphenoidal approach. In 3 cases, other approaches were applied. Gross-total resection was achieved in 43 patients (59.7\%), near-total resection in 28 (38.9\%), and partial resection in only 1 patient (1.4\%). The mean follow-up period after resection was 4.7 years. Tumor recurrence or regrowth occurred in $15(20.8 \%)$ of the 72 patients, with 14 of the 15 cases successfully controlled after additional resections and stereotactic radiosurgery. However, 1 patient died of uncontrollable tumor progression, and 2 patients died of unrelated diseases during the follow-up. Overall, disease in $69(95.8 \%)$ of 72 patients was well controlled at the last follow-up.

CONCLUSIONS Aggressive tumor resection is the authors' treatment policy for craniopharyngioma. Using an anatomical subclassification of craniopharyngioma to choose the most appropriate surgical approach is helpful in achieving that goal of aggressive resection.

https://thejns.org/doi/abs/10.3171/2016.9.FOCUS16211

KEY WORDS craniopharyngioma; surgical management; outcome; anatomical subclassification

$\mathrm{E}$ VEN with the recent advances in surgical equipment and techniques, craniopharyngiomas have remained a particularly formidable challenge in the neurosurgical field. ${ }^{6,9,12}$ Because of the craniopharyngioma's anatomical location and proximity to critical neurovascular structures, including the hypothalamus and ophthalmological systems, its resection is associated with either higher rates of mortality and recurrence or a lower rate of radical resection. ${ }^{4,9,12}$ Various surgical options for removing craniopharyngiomas, such as the pterional, orbitozygomatic, transbasal subfrontal, frontobasal interhemispheric, and transnasal transsphenoidal approaches, have been described. However, the optimal surgical approach remains controversial. ${ }^{4,6,8,10,12,21,24,25}$

ABBREVIATIONS GTR = gross-total resection; KPS = Karnofsky Performance Scale; NTR = near-total resection; PR = partial resection; STR = subtotal resection; VIS = visual impairment score. 


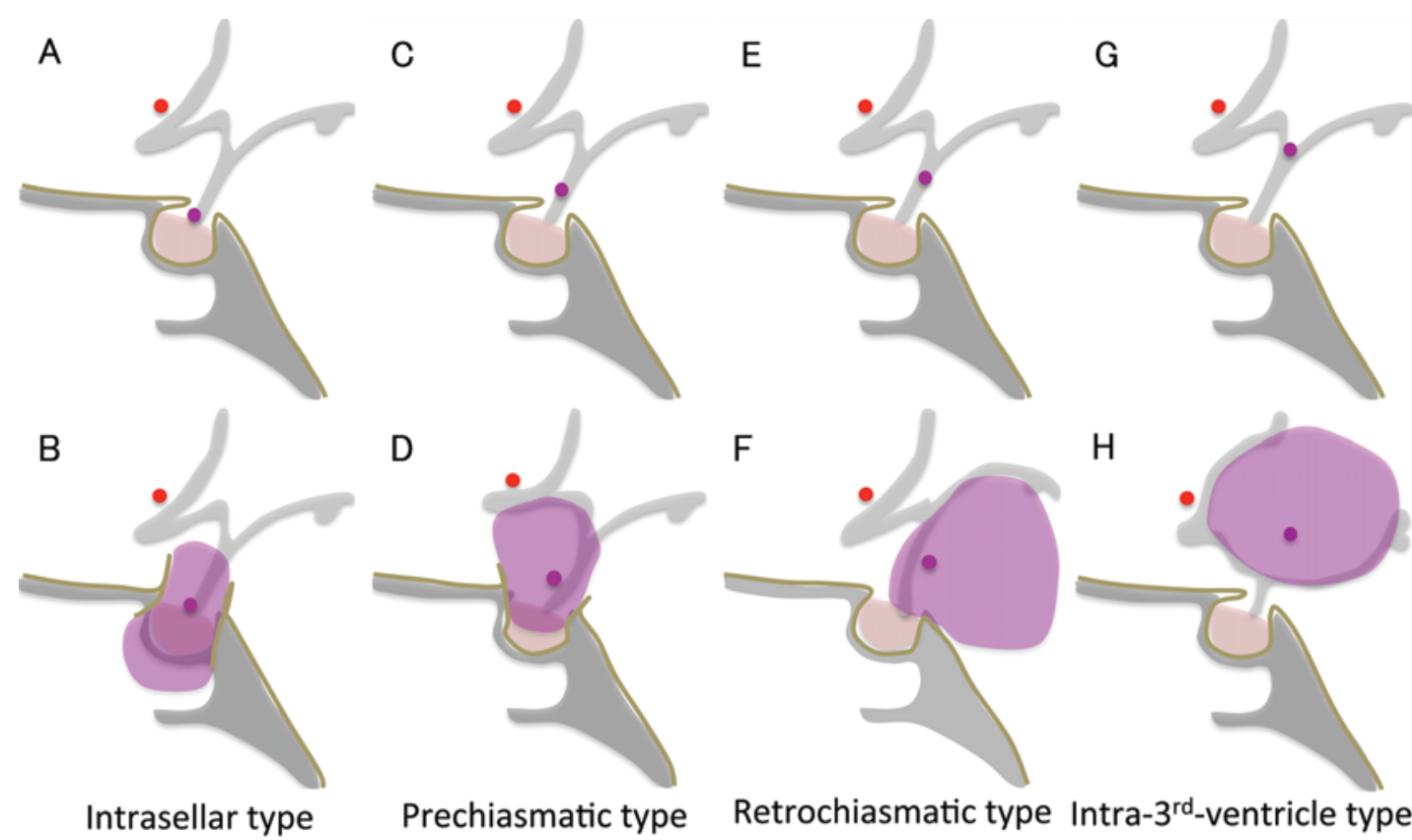

FIG. 1. Anatomical subclassification of craniopharyngiomas. A and B: If a tumor originates from the intrasellar part of the stalk, it is defined as the "intrasellar type." In these cases, the sellar floor is usually enlarged. C and D: If a tumor originates from the anterior part of the stalk and grows upward, it is defined as the "prechiasmatic type." Both the optic chiasm and the anterior communicating artery are also elevated upward in this lesion type. E and F: If a tumor originates from the posterior part of the stalk and grows up toward the posterior fossa, it is defined as the "retrochiasmatic type." Both the optic chiasm and the anterior communicating artery remain in their normal positions. $\mathbf{G}$ and $\mathbf{H}$ : If a tumor originates from the floor of the third ventricle, it is defined as the "intra-third ventricle type." Red dots indicate the anterior communicating artery. Purple dots indicate the origin of the tumor.

To select the most appropriate surgical approach for treating these lesions, we created a new subclassification of craniopharyngiomas that was based on the anatomical location of the tumor. To determine the viability of this new strategy, we surgically treated patients with craniopharyngiomas in accordance with this anatomical classification and then examined patient outcomes. In many of the complicated cases, we performed multistage surgery to maintain normal function in patients.

This report contains information on a surgical strategy that was based on an anatomical subclassification of craniopharyngiomas. We also present the results of our analysis of the treatments and outcomes for a consecutive series of craniopharyngioma cases, which included evaluations of the extent of tumor resection, tumor control, surgical complications, visual function, endocrinological status, neuropsychological function, and functional performance status.

\section{Methods}

Clinical and ophthalmological examinations, imaging studies, endocrinological studies, neuropsychological function, and surgical complications in all patients who had undergone microsurgical resection for craniopharyngioma at Osaka City University hospital between January 2000 and December 2014 were retrospectively reviewed through the medical records.

\section{Anatomical Subclassification of Craniopharyngiomas}

We classified craniopharyngiomas based on their lo- cation, origin, and growth pattern. The 4 groups defined in our classification scheme and used to choose the appropriate treatment approach include the intrasellar, prechiasmatic, retrochiasmatic, and intra-third ventricle type (Fig. 1).

The intrasellar type of craniopharyngioma originates from the intrasellar part of the stalk. In this lesion type, the sellar floor is usually enlarged in a manner similar to that seen for a pituitary adenoma (Fig. 1A and B). The prechiasmatic type originates from the anterior part of the stalk and grows in an upward direction. There is also upward elevation of the optic chiasm and anterior communicating artery, with tumor extending to the lateral side (Fig. $1 \mathrm{C}$ and $\mathrm{D})$. The retrochiasmatic type originates from the posterior part of the stalk and grows up toward the posterior fossa. The optic chiasm and anterior communicating artery remain in their normal positions (Fig. 1E and F). The intra-third ventricle type originates from the floor of the third ventricle (Fig. $1 \mathrm{G}$ and $\mathrm{H}$ ).

\section{Surgical Strategies Based on the Anatomical Subclassification}

Aggressive resection of the craniopharyngioma was originally planned in all of the patients who were evaluated. Subsequently, the actual initial surgical approach was chosen in accordance with the anatomical subclassification (Fig. 2). For the intrasellar type of craniopharyngioma, an endoscopic or microscopic transsphenoidal approach was applied. For the prechiasmatic type without lateral extension, we applied the extended transsphenoi- 


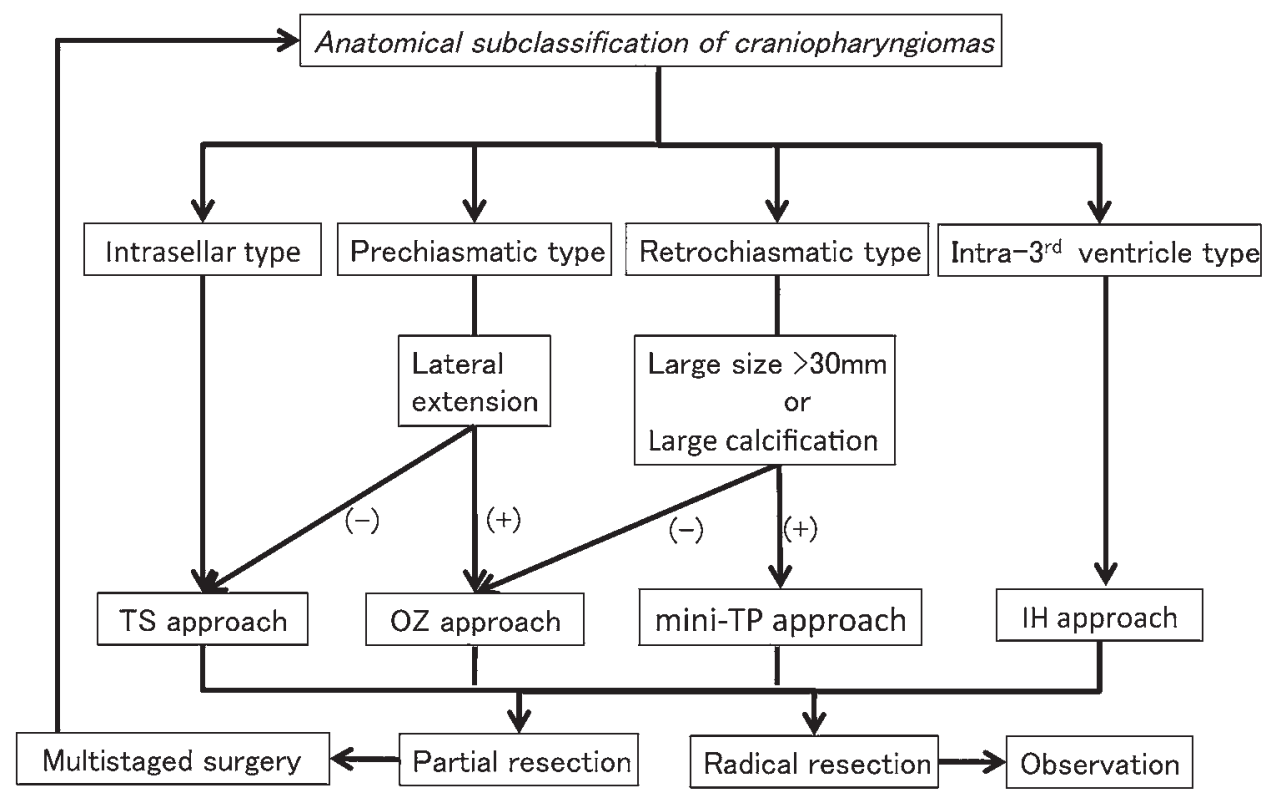

FIG. 2. Surgical strategies based on an anatomical subclassification of craniopharyngioma. Aggressive resection of the lesion was planned in all patients, with the initial surgical approach then determined according to the anatomical subclassification. Lesions with complicated conditions were treated using a multistage surgery, with the surgical approach for the remaining portion of the tumor selected according to a reevaluation of the area using the anatomical subclassification. $\mathrm{IH}=$ interhemispheric; $\mathrm{OZ}=$ orbitozygomatic; TP = transpetrosal; TS = transsphenoidal.

dal approach, whereas the orbitozygomatic approach was used for the prechiasmatic type with lateral extension. For the small retrochiasmatic lesion type without extensive calcification, we selected the orbitozygomatic approach, and the mini-transpetrosal approach was used for the retrochiasmatic type with extensive calcification or a large diameter $(>30 \mathrm{~mm})$. For the intra-third ventricle type, we applied the interhemispheric translamina terminalis approach to provide a suitable surgical corridor.

When cases had complicated conditions such as a history of excision or radiotherapy, extensive calcification, a large diameter $(>30 \mathrm{~mm})$, superior extension into the third ventricle, or severe posterior extension compressing the midbrain and pons, multistage surgery was selected. The surgical approaches for the remaining tumor portions were then selected after a reevaluation and in accordance with the anatomical subclassification. If the tumor tightly adhered to small perforating arteries from the internal carotid artery, we stopped the tumor resection.

\section{Neuroradiological Evaluation}

Before surgery, all patients underwent MRI, CT, and angiography. Tumor size was estimated from MR images by measuring the maximum anteroposterior, vertical, and horizontal diameters. The extent of intratumoral calcification was determined on CT scans. Anatomical features of the cerebral vessels, such as extent of development of the posterior communicating artery and development of venous drainage on the lesion side, were evaluated on angiograms.

To assess the extent of tumor resection, neuroradiologists independently reviewed the results of the preoperative and postoperative MR and CT images. All images used in the assessments were obtained within 1 week after surgery and from the follow-up radiological studies. All tumors were evaluated using enhanced MRI. Small enhancing lesions that diminished in the late period were judged to represent postoperative reactive changes rather than residual tumor.

Resection classifications were determined as follows. Gross-total resection (GTR) was defined as no residual enhanced lesion or residual calcification. Near-total resection (NTR) was defined as residual enhanced lesion or calcification $<0.5 \mathrm{~cm}^{3}$. Partial resection (PR) was defined as residual enhanced lesion or calcification $\geq 0.5 \mathrm{~cm}^{3}$.

\section{Visual Function}

Ophthalmological evaluation, including visual acuity and visual field examinations in accordance with guidelines of the German Ophthalmological Society, was performed by an ophthalmologist before and after surgery and when clinically appropriate. The timing of subsequent assessments was decided on an individual basis. Visual function in each patient was quantified by the visual impairment score (VIS), which is based on visual acuity and visual field defects in both eyes. ${ }^{7}$ This score, the summed total of the scores for visual acuity and visual field defects, made it possible to perform an exact comparison between the different examinations in each of the patients. A score of 100 is defined as the maximum.

\section{Endocrinological Status}

Basic levels of luteinizing hormone, follicle-stimulating hormone, free triiodothyronine, free thyroxine, thyroid-stimulating hormone, growth hormone, cortisol, adrenocorticotropic hormone, and prolactin were evaluated before and after surgery. Anterior pituitary hormone dys- 

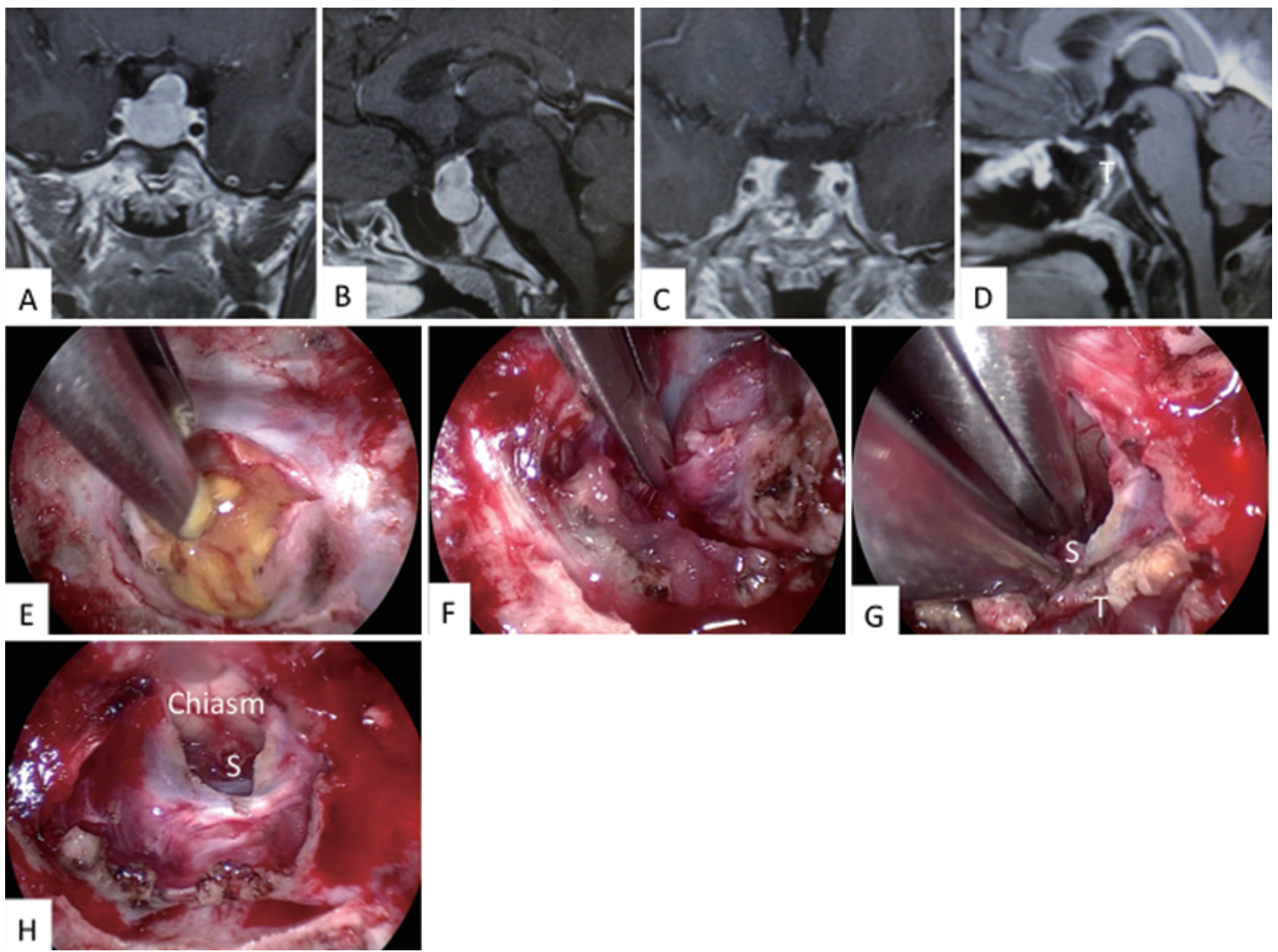

FIG. 3. Case 1. Preoperative coronal (A) and sagittal (B) enhanced T1-weighted MR images show typical findings for the intrasellar type of craniopharyngioma. Postoperative coronal (C) and sagittal (D) enhanced T1-weighted images show total tumor removal achieved via an endoscopic endonasal transsphenoidal approach. For the intrasellar type of craniopharyngioma, the anatomical relationship between tumor and surrounding structures is similar to that seen for a pituitary adenoma. The sellar floor is usually enlarged $(\mathbf{E})$, and since the suprasellar side of the tumor is often covered by extended diaphragm, there is no adhesion with the tumor or the other important blood vessels $(\mathbf{F})$. In this particular case, the tumor had invaded all parts of the stalk, which required resection of the tumor including the stalk during the final phase $(\mathbf{G})$. Image showing complete removal of the tumor $(\mathbf{H}) . \mathrm{S}=\mathrm{stalk}$; $\mathrm{T}$ $=$ tumor.

function was defined as the use of hormone supplementation (for deficits in the basic levels of luteinizing hormone, follicle-stimulating hormone, free triiodothyronine, free thyroxine, thyroid-stimulating hormone, growth hormone, cortisol, or adrenocorticotropic hormone) or the presence of high levels of prolactin without the use of dopamine agonists. Diabetes insipidus was diagnosed before and after surgery based on the sodium level and the presence of hypotonic polyuria.

\section{Neuropsychological Function and Performance Status}

Neuropsychological function was evaluated preoperatively and postoperatively during face-to-face examinations. Patients were considered to have a neuropsychological deficit if any of the following conditions were met: 1) score $<70$ on the Full Scale of the Wechsler Adult Intelligence Scale, 3rd edition; 2) score $<20$ on the Mini-Mental State Examination; or 3) the patient found it impossible to continue in a previous occupation because of the presence of the lesion. ${ }^{12}$

Functional performance status was evaluated using the Karnofsky Performance Scale (KPS).

\section{Tumor Recurrence}

Recurrence of the tumor during follow-up was defined as the appearance of new pathological tissue on MR images or the growth of tumor remnants. Follow-up MRI was performed within 1 week and within 3 months after surgery and then at regular intervals of 6-12 months.

\section{Statistical Analysis}

Data were analyzed using the Mann-Whitney U-test for unpaired samples or the Wilcoxon t-test for paired samples. Differences correlating to an error of probability < 0.05 were considered statistically significant. The cumulative risk of tumor recurrence was calculated according to the Kaplan-Meier method using JMP version 9.0 software (SAS Institute Inc.).

\section{Illustrative Cases}

\section{Case 1: Intrasellar Type}

An intrasellar lesion was detected in an 11-year-old boy suffering from diabetes insipidus (Fig. 3A and B). Preoperative MRI demonstrated characteristic findings of 

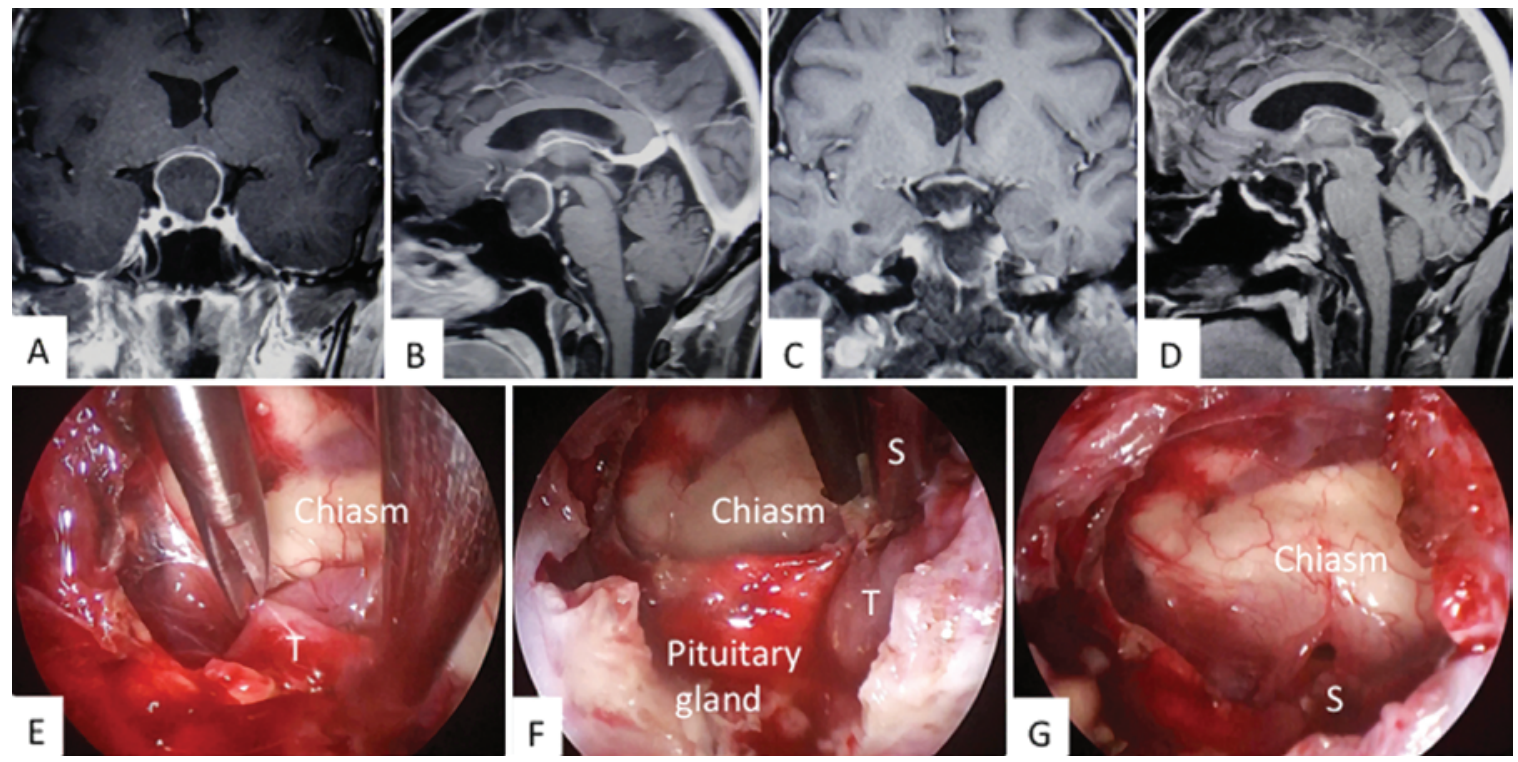

FIG. 4. Case 2. Preoperative coronal (A) and sagittal (B) enhanced T1-weighted MR images showing elevation of the optic chiasm and the anterior communicating artery. No lateral extension of the tumor was observed. Postoperative coronal (C) and sagittal (D) enhanced T1-weighted MR images showing total tumor removal achieved via an endoscopic endonasal transsphenoidal approach. Bone was removed from the sellar floor to the tuberculum sellae. We carefully dissected tumor off of any adjacent critical neurovascular structures, including the optic chiasm and many perforating arteries $(E)$. In this particular case, normal pituitary gland was located on the right side of the tumor $(\mathbf{F})$, and since the tumor did not invade all parts of the stalk, we were able to preserve the stalk (G).

the intrasellar type of craniopharyngioma. After applying the endoscopic endonasal transsphenoidal approach for this lesion, bone was removed from the sellar floor to the tuberculum sellae (Fig. 3E). The tumor was then carefully dissected off of any adjacent critical neurovascular structures (Fig. 3F and G) and totally removed (Fig. 3D, $\mathrm{E}$, and $\mathrm{H})$.

\section{Case 2: Prechiasmatic Type Without Lateral Extension}

A 52-year-old female exhibiting deterioration in her visual acuity on the right side was referred to our hospital. Preoperative MRI demonstrated elevation of the optic chiasm and anterior communicating artery and no lateral extension of the tumor (Fig. 4A and B). The tumor was totally removed via the endoscopic endonasal transsphenoidal approach, as it provided a large enough surgical corridor (Fig. 4C-G).

\section{Case 3: Prechiasmatic Type With Lateral Extension}

A 49-year-old male with a 3-month history of deteriorating visual acuity on the left side was referred to our hospital. Preoperative MRI demonstrated elevation of the optic chiasm and anterior communicating artery, with tumor extended outside and beyond the left internal carotid artery (Fig. 5A and B). The tumor was totally removed via a left orbitozygomatic approach (Fig. $5 \mathrm{C}-\mathrm{H}$ ).

\section{Case 4: Small Retrochiasmatic Type Without Extensive Calcification}

A 61-year-old male presented with visual acuity deterioration of 1 year's duration on his left side. The tumor diameter was $28 \mathrm{~mm}$, and no extensive calcification was observed (Fig. 6A-C). Typical of the retrochiasmatic type, the lesion in this case did not exhibit any elevation of the anterior communicating artery. The tumor was totally removed via the left orbitozygomatic approach as this provided large enough surgical corridors through the prechiasmatic, retrocarotid, and opticocarotid spaces (Fig. 6D-H).

\section{Case 5: Large Retrochiasmatic Type}

A 35-year-old woman presented with deterioration of both her visual acuity and her visual field. The tumor diameter was $45 \mathrm{~mm}$, and no extensive calcification was observed (Fig. 7A-C). Typical of the retrochiasmatic type of lesion, there was no elevation of the anterior communicating artery. The left transpetrosal approach was selected with the aim of radical resection. The main part of the tumor was removed through the surgical window between the posterior communicating artery and the oculomotor nerve (Fig. 7F-H). This made it possible to completely remove the tumor (Fig. 7D, E, and I).

\section{Case 6: Intra-Third Ventricle Type}

A 43-year-old male presented with a loss of social activity for the previous year. Preoperative MRI demonstrated characteristic findings for the intra-third ventricle type of craniopharyngioma (Fig. 8A and B). Although we selected the interhemispheric translamina terminalis approach, the tumor could not be removed through the prechiasmatic space (Fig. 8E). However, we were able to excise the majority of tumor through the lamina terminalis just above the anterior communicating artery (Fig. $8 \mathrm{~F}$ and $\mathrm{G}$ ). Unfortunately, the bottom part of the tumor was obstructed by 

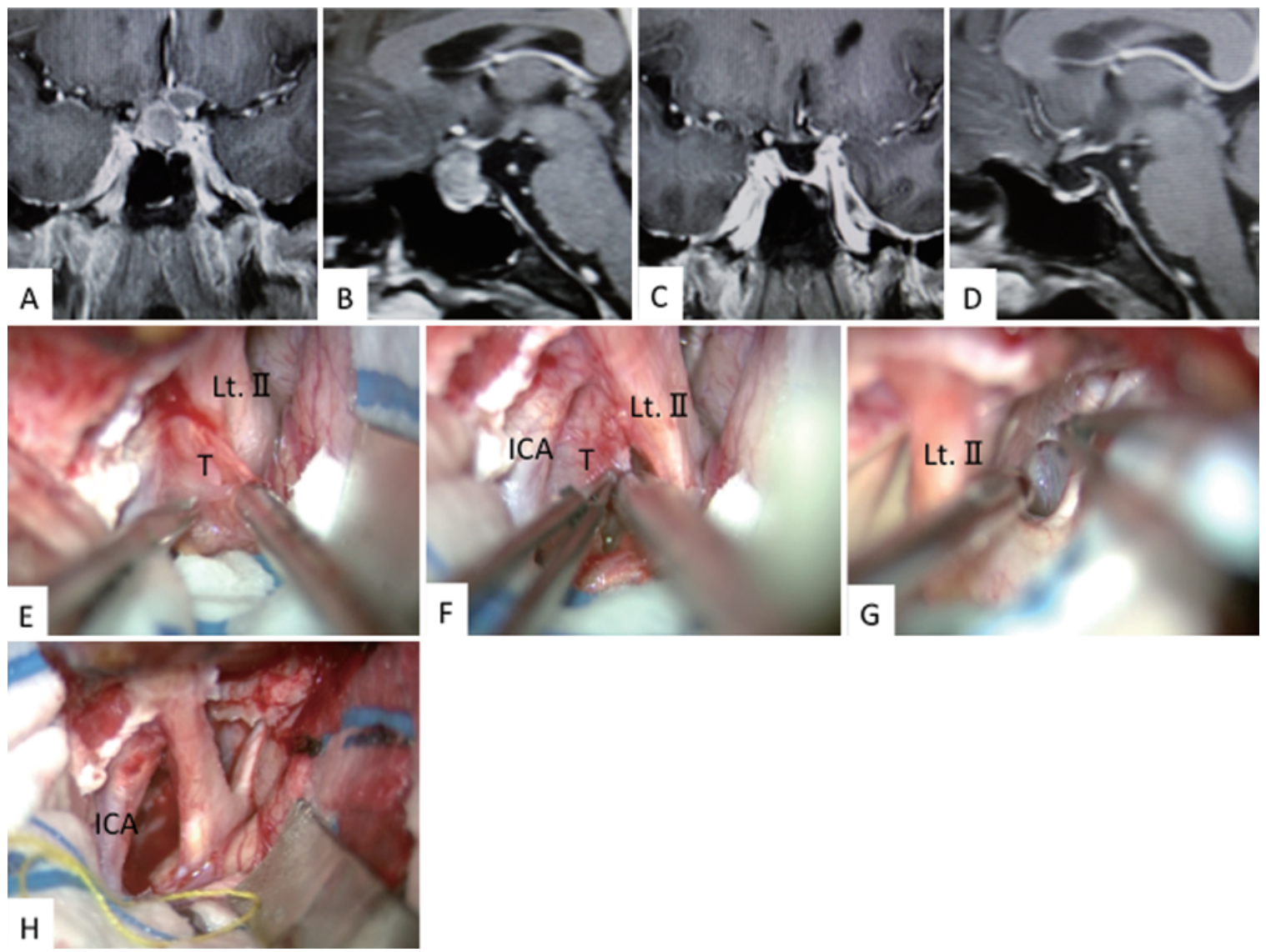

FIG. 5. Case 3. Preoperative coronal (A) and sagittal (B) enhanced T1-weighted MR images showing elevation of the optic chiasm and anterior communicating artery as well as lateral extension of the tumor. Postoperative coronal (C) and sagittal (D) enhanced T1-weighted MR images showing total tumor removal achieved via a left orbitozygomatic approach. Tumor extended to outside and beyond the left internal carotid artery $(E)$. The surgical corridor through the opticocarotid space $(\mathbf{F})$. The surgical corridor through the prechiasmatic space (G). Total tumor removal (H). ICA = internal carotid artery; Lt. II = left optic nerve.

the anterior communicating artery and optic chiasm (Fig. $8 \mathrm{H})$. Residual tumor was finally totally removed via the right orbitozygomatic approach (Fig. 8C and D).

\section{Results}

\section{Patient Population}

Between January 2000 and December 2014, 72 consecutive patients with craniopharyngiomas underwent microsurgical resection at Osaka City University hospital. Medical records for all 72 patients were retrospectively reviewed. This group consisted of 36 males and 36 females, with a mean age of 37.7 years (range 3-71 years) at the time of surgery (Table 1). Thirty-two patients $(44.4 \%)$ had undergone surgical procedures at other institutions before presenting to us. The mean follow-up duration was 4.7 years (range 10-189 months). All patients underwent neuroimaging and neurological follow-up at intervals of 6-12 months.

\section{Tumor Characteristics}

Of the 72 tumors examined in this study, 35 (48.6\%) were classified as the retrochiasmatic type, 19 (26.4\%) as the prechiasmatic type, $12(16.7 \%)$ as the intra-third ventricle type, and $6(8.3 \%)$ as the intrasellar type (Table
1). The mean maximum tumor diameter, which was estimated from preoperative MR images, was $30.2 \mathrm{~mm}$ (range $7-64 \mathrm{~mm})$.

Table 2 lists data for the multistage surgery, which was performed in $26(36.1 \%)$ of the 72 patients. With regard to the approach used for the tumors, 41 were resected via the orbitozygomatic approach, 21 via the interhemispheric approach, 21 via the transsphenoidal approach, 14 via the transsphenoidal approach, and 3 via other approaches.

Multistage surgery was used to remove $15(42.8 \%)$ of 35 retrochiasmatic type tumors. The orbitozygomatic approach was used to resect 22 retrochiasmatic type craniopharyngiomas, the transpetrosal approach to resect 21 , the interhemispheric approach to resect 5, the transsphenoidal approach to resect 1 , and other approaches to resect 3 .

Multistage surgery was used to remove $3(15.8 \%)$ of the 19 prechiasmatic type of tumors. The orbitozygomatic approach was used to resect 11 prechiasmatic lesions, the transsphenoidal approach to resect 7, and the interhemispheric approach to resect 4.

Of the 12 intra-third ventricle type tumors, 7 (58.3\%) were removed via multistage surgery. The interhemispheric approach was used to resect 12 of these lesions, while the orbitozygomatic approach was used to resect 7 .

Of the 6 intrasellar type of tumors, 1 (16.7\%) was re- 

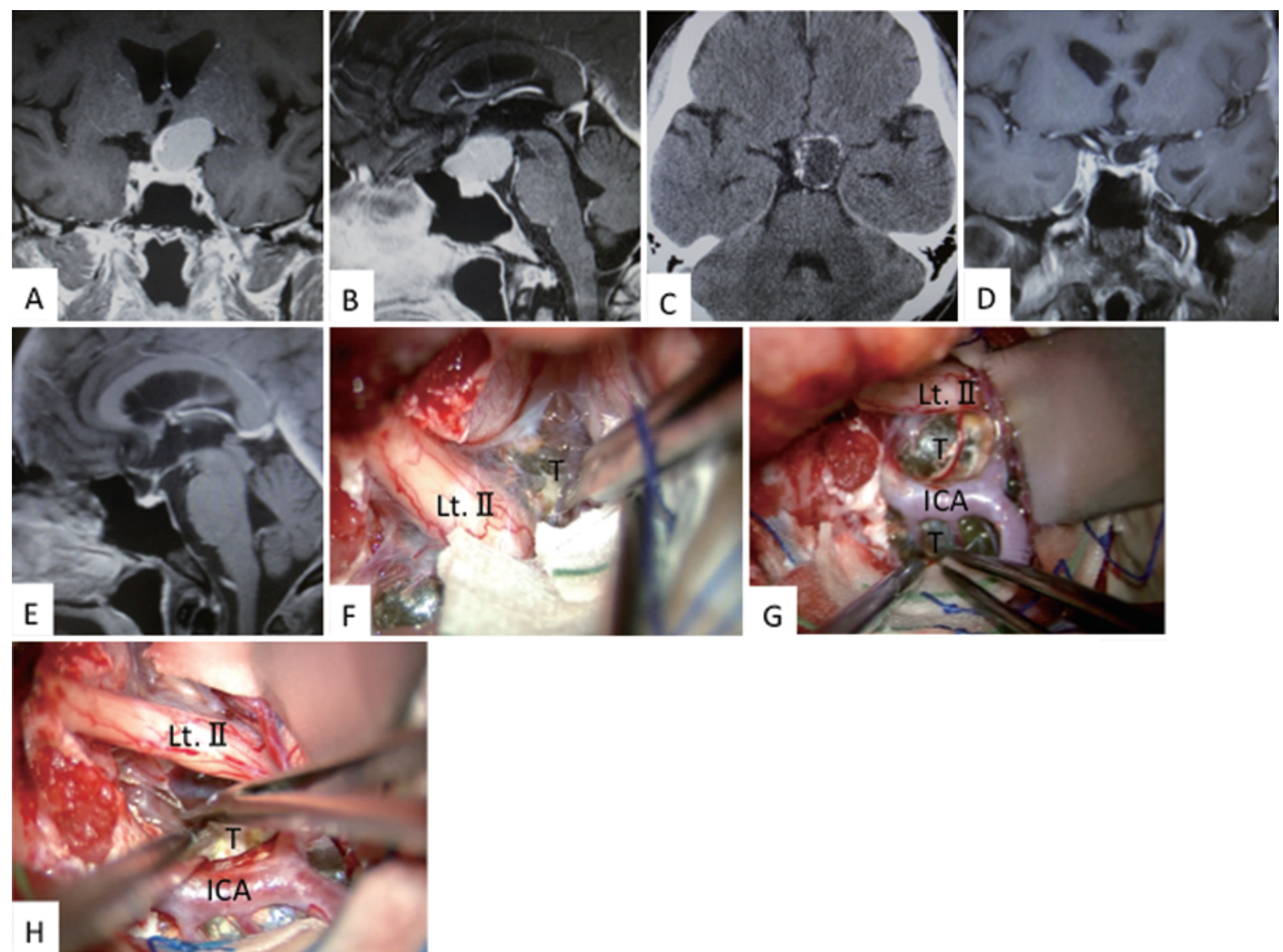

FIG. 6. Case 4. Preoperative coronal (A) and sagittal (B) enhanced T1-weighted MR images showed that the anterior communicating artery was not elevated, which is a typical finding for the retrochiasmatic type of craniopharyngioma. CT scan showing tumor included a small calcified portion (C). Postoperative coronal (D) and sagittal (E) enhanced T1-weighted MR images showing total tumor removal via the left orbitozygomatic approach. The surgical corridor through the prechiasmatic space (F). The surgical corridor through the retrocarotid space $(\mathbf{G})$. The surgical corridor through the opticocarotid space $(\mathbf{H})$.

moved via multistage surgery. The transsphenoidal approach was used to resect 6 , whereas the orbitozygomatic approach was used to resect 1 .

\section{Extent of Tumor Resection}

Table 2 shows data on extent of tumor resection. Among the 72 cases, GTR was achieved in $43(59.7 \%)$ whereas NTR was achieved in 28 (38.9\%). Partial resection was achieved in only 1 patient (1.4\%).

For the retrochiasmatic type of tumors, GTR was achieved in $20(57.1 \%)$ of 35 patients and NTR in 15 $(42.9 \%)$. For the prechiasmatic type of tumors, GTR was achieved in $12(63.1 \%)$ of 19 patients, NTR in $6(31.6 \%)$, and PR in $1(5.3 \%)$. For the intra-third ventricle type of tumors, GTR was achieved in 9 (75.0\%) of 12 patients, NTR in $3(25.0 \%)$, and PR in none. For the intrasellar type of tumors, GTR was achieved in $2(33.3 \%)$ of 6 patients, NTR in 4 (66.7\%), and PR in none (Table 2).

\section{Complications}

No surgery-related deaths occurred among the 72 patients. Oculomotor nerve palsy was confirmed in 1 patient who underwent the orbitozygomatic approach, whereas hearing loss was confirmed in 1 patient who underwent the transpetrosal approach. No other cranial nerve pal- sies were seen. Postoperative hemorrhage occurred in 1 patient who underwent the orbitozygomatic approach and required the removal of a hematoma. Leakage of CSF occurred in 1 patient who underwent the transpetrosal approach, which required repair of the leak.

\section{Visual Function}

Table 3 lists the mean preoperative and postoperative VISs. Prior to surgery, 59 (81.9\%) of 72 patients exhibited visual disturbance; after surgery, 24 (40.7\%) of these 59 patients had improved visual function. Also after surgery, $43(59.7 \%)$ of the 72 patients exhibited no deterioration in visual function, whereas 5 patients (6.9\%) experienced some deterioration. Overall, the mean VIS score improved from $28.7 \pm 27.6$ preoperatively to $21.8 \pm 25.6$ postoperatively.

Of the 35 patients with the retrochiasmatic tumor type, 27 (77.1\%) exhibited visual disturbance before surgery, but improvement was seen in 12 of these patients (44.4\%) after surgery. No deterioration in visual function occurred in 20 (57.1\%) of the 35 patients, whereas some deterioration was noted after surgery in 3 patients $(8.6 \%)$. The mean VIS score in patients in the retrochiasmatic group improved from $28.7 \pm 31.2$ preoperatively to $19.9 \pm 26.2$ postoperatively. 

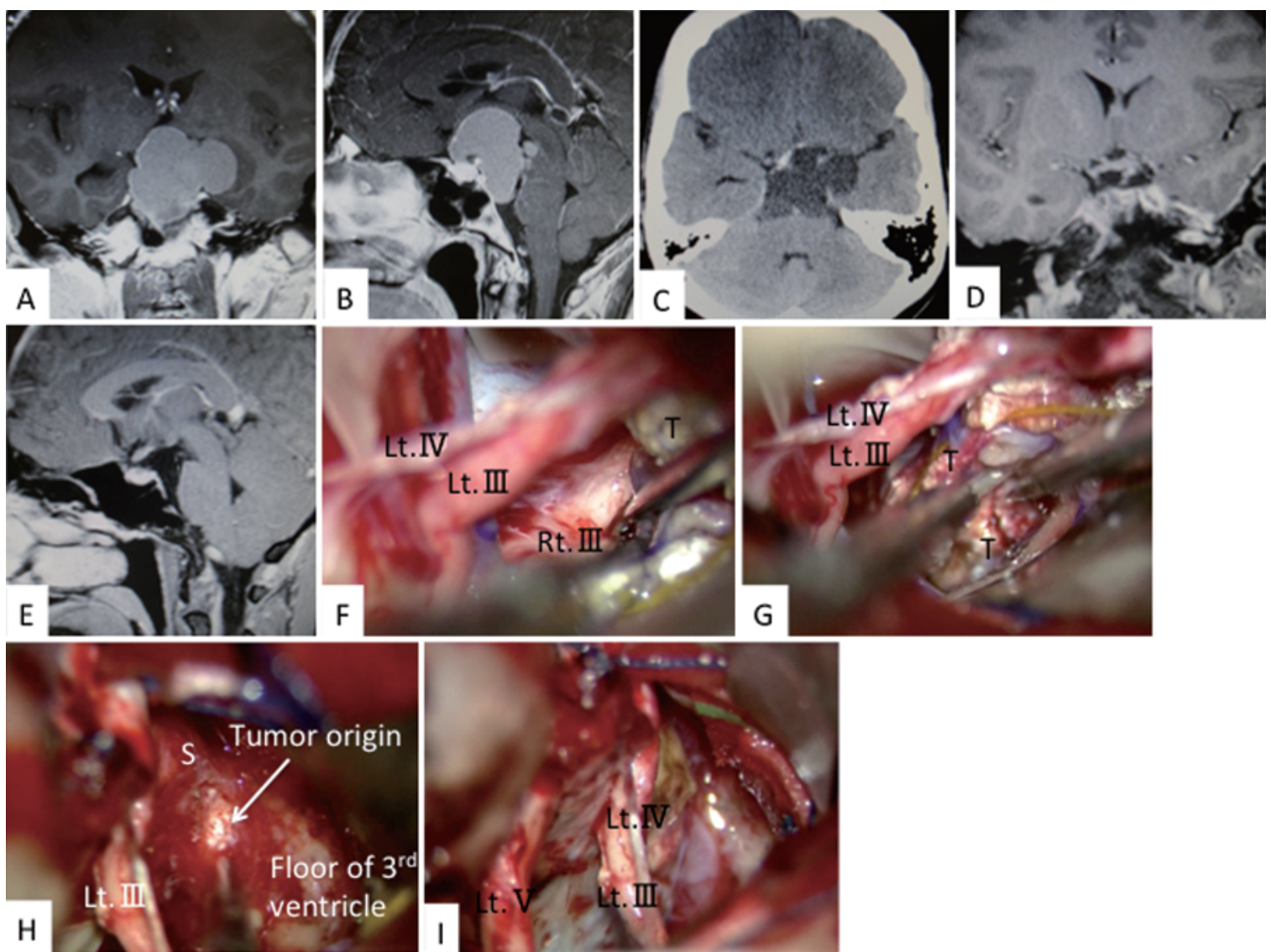

FIG. 7. Case 5. Preoperative coronal (A) and sagittal (B) enhanced T1-weighted MR images show that the anterior communicating artery was not elevated, which is a typical finding for the retrochiasmatic type. CT scan showing tumor included a small calcified portion (C). Postoperative coronal (D) and sagittal (E) enhanced T1-weighted MR images showing total tumor removal achieved using the left combined transpetrosal approach. The oculomotor nerve on the opposite side could be observed in the inferior-tosuperior surgical trajectory (F). Most of the tumor was removed via the surgical window between the posterior communicating artery and the oculomotor nerve $(\mathbf{G})$. Use of the transpetrosal approach made it possible to visualize the retrochiasmatic area including the origin of the tumor $(\mathbf{H})$. The tumor was totally removed $(\mathrm{I})$. Lt. IV = left trochlear nerve; Rt. III = right oculomotor nerve.

Among the 19 patients with prechiasmatic tumors, 18 (94.7\%) showed visual disturbance before surgery, but improvement was observed in 4 of them $(22.2 \%)$ after surgery. No deterioration of visual function was observed postoperatively in 13 patients $(68.4 \%)$ in the retrochiasmatic group, whereas 2 (10.5\%) did experience some deterioration. The mean VIS score remained relatively the same before and after surgery: $32.7 \pm 26.0$ preoperatively and $29.9 \pm 30.2$ postoperatively.

Among the 12 patients with the intra-third ventricle type of tumor, $9(75.0 \%)$ exhibited visual disturbance before surgery; 5 (55.6\%) of the 9 had improvement after surgery. There was no deterioration in visual function in $7(58.3 \%)$ of the 12 patients after surgery. The mean VIS score improved from $21.4 \pm 20.7$ preoperatively to $14.6 \pm$ 13.8 postoperatively in this group.

In the intrasellar type of tumors, $5(83.3 \%)$ of 6 patients exhibited visual disturbance before surgery; $3(60.0 \%)$ of the 5 had improvement after surgery. No deterioration in visual function was observed in $3(50.0 \%)$ of the 6 patients after surgery. The mean VIS score in patients with the intrasellar tumor type improved from $29.0 \pm 23.1$ preoperatively to $19.0 \pm 20.6$ postoperatively.

\section{Endocrinological Status}

Preoperatively, 49 patients (68.1\%) showed some deficit in anterior pituitary hormone, and 34, 30, 13, and 17 patients had a preoperative deficit in adrenal, thyroid, gonadal, or somatotroph function, respectively. Twenty-five patients (34.7\%) had diabetes insipidus preoperatively. Postoperatively, 64 patients $(88.9 \%)$ received replacement of anterior pituitary hormone and 52 patients (72.2\%) had diabetes insipidus (Table 3).

Twenty-four patients $(68.6 \%)$ with the retrochiasmatic tumor type showed some deficit in anterior pituitary hormone, and 13, 9, 6 , and 6 patients had a preoperative deficit in adrenal, thyroid, gonadal, or somatotroph function, respectively. Fifteen patients $(42.8 \%)$ had diabetes insipidus preoperatively. Postoperatively, 31 patients $(88.6 \%)$ received replacement of anterior pituitary hormone and 29 patients (82.9\%) had diabetes insipidus.

Among the patients with the prechiasmatic type of tumors, 14 (73.7\%) showed some deficit in anterior pituitary hormone, and 14, 12, 3, and 3 patients had a preoperative deficit of adrenal, thyroid, gonadal, or somatotroph function, respectively. Preoperatively, 7 patients (36.8\%) had 

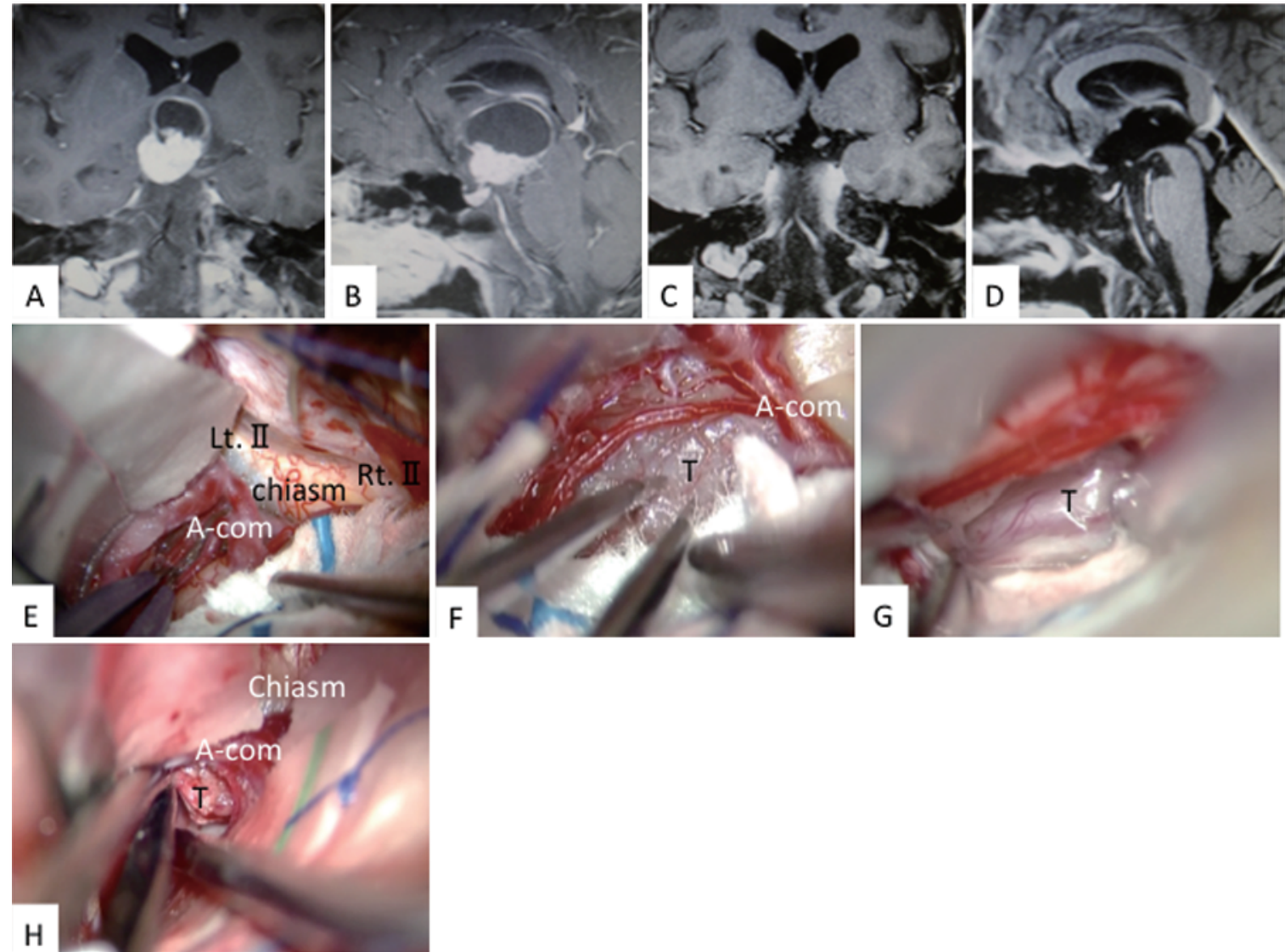

FIG. 8. Case 6. Preoperative coronal (A) and sagittal (B) enhanced T1-weighted MR images show enlargement of the third ventricle, which is a typical finding for the intra-third ventricle type of craniopharyngioma. Postoperative coronal (C) and sagittal (D) enhanced T1-weighted MR images showing total tumor removal by the interhemispheric translamina terminalis approach and the right orbitozygomatic approach. The tumor could not be removed through the prechiasmatic space (E). The surgical window at the lamina terminalis was a narrow space located between the hypothalamic perforators $(\mathbf{F})$. The majority of tumor was excised via the lamina terminalis just above the anterior communicating artery $(\mathbf{G})$. The bottom part of the tumor was obstructed by the anterior communicating artery and optic chiasm $(\mathrm{H})$. A-com = anterior communicating artery; $\mathrm{Rt}$. $\mathrm{II}=$ right optic nerve.

diabetes insipidus. Postoperatively, 16 patients $(84.2 \%)$ received replacement of anterior pituitary hormone and 10 patients $(52.6 \%)$ had diabetes insipidus.

Among patients with the intra-third ventricle type of tumor, 7 (58.3\%) showed some deficit in anterior pituitary hormone, and 4,5,3, and 7 patients had a preoperative deficit in adrenal, thyroid, gonadal, or somatotroph function, respectively. None of the patients with this tumor type had diabetes insipidus preoperatively. Postoperatively, 12 patients $(100 \%)$ received replacement of anterior pituitary hormone and 12 patients (100\%) had diabetes insipidus.

Four patients (66.7\%) with the intrasellar tumor type had some deficit in anterior pituitary hormone, and 3, 4, 1 , and 1 patient had a preoperative deficit in adrenal, thyroid, gonadal, or somatotroph function, respectively. Three patients $(50.0 \%)$ had diabetes insipidus preoperatively. Postoperatively, 5 patients $(83.3 \%)$ received replacement of anterior pituitary hormone and 3 patients $(50.0 \%)$ had diabetes insipidus.

\section{Obesity}

Prior to surgery, 10 (13.9\%) of the 72 patients were considered to be obese (Table 3). During follow-up, 19 patients
(26.4\%) were obese. Seven patients $(20.0 \%)$ with the retrochiasmatic type of tumor were obese before surgery. There was a slight increase in obesity during the follow-up among this group, with 11 patients $(31.4 \%)$ defined as obese. Among the 19 patients with the prechiasmatic tumor type, $2(10.5 \%)$ were classified as obese before surgery. During follow-up, 5 patients $(26.3 \%)$ were classified as obese. Among the 12 patients with the intra-third ventricle tumor type, obesity was noted in $1(8.3 \%)$ before surgery, whereas 3 patients (25.0\%) were obese during the follow-up. None of the patients with the intrasellar tumor type was obese either before the surgery or at the last follow-up.

\section{Neuropsychological Function}

Before surgery, 12 (16.7\%) of the 72 patients exhibited a neuropsychological deficit (Table 3). During follow-up, neuropsychological status was preserved in 70 patients (97.2\%) and improved in $2(2.8 \%)$. None of the patients exhibited any deterioration in neuropsychological function after the surgery.

Among the 35 patients with the retrochiasmatic type of tumor, 7 (20.0\%) showed a neuropsychological deficit before surgery. During the follow-up, neuropsychological 
TABLE 1. Tumor characteristics in each group according to an anatomical subclassification of craniopharyngiomas

\begin{tabular}{llcccc}
\hline \multicolumn{1}{c}{ Variable } & All Patients & Intrasellar Type & Prechiasmatic Type & Retrochiasmatic Type & Intra-Third Ventricle Type \\
\hline No. of patients & 72 & $6(8.3 \%)$ & $19(26.4 \%)$ & $35(48.6 \%)$ & $12(16.7 \%)$ \\
\hline Mean age (yrs) & 37.7 & 22.3 & 33.5 & 40.1 & 45.1 \\
\hline Sex (M/F) & $36 / 36$ & $4 / 2$ & $11 / 8$ & $14 / 21$ & $7 / 5$ \\
\hline Previous op \&/or radiation & $32(44.4 \%)$ & $2(33.3 \%)$ & $10(52.6 \%)$ & $18(48.6 \%)$ & $2(16.7 \%)$ \\
\hline Mean tumor diameter (mm) & 30.2 & 34.3 & 28.4 & 40.0 & 28.5 \\
\hline
\end{tabular}

status was preserved in 33 patients $(94.3 \%)$ and improved in $2(5.7 \%)$.

Among the 19 patients with the prechiasmatic type of tumor, 1 patient $(5.3 \%)$ exhibited a neuropsychological deficit prior to surgery. During follow-up, neuropsychological status was preserved in all 19 patients $(100 \%)$ with this tumor type.

In the group with the intra-third ventricle tumor type, $3(25.0 \%)$ of the 12 patients demonstrated a neuropsychological deficit before surgery. During follow-up, neuropsychological status was preserved in all 12 patients (100\%).

Among the 6 patients with the intrasellar tumor type, $1(16.7 \%)$ exhibited a neuropsychological deficit prior to surgery. During follow-up, neuropsychological status was preserved in all 6 patients $(100 \%)$.

\section{Functional Performance Status}

The mean preoperative KPS score was 83.2 (range 50-100), whereas the mean postoperative score was 86.0 (range 50-100; Table 3). The scores improved in 19 patients $(26.4 \%)$ and remained stable in $53(73.6 \%)$. None of the patients showed any deterioration in the KPS score after surgery.

The mean preoperative and postoperative KPS scores for patients with the retrochiasmatic tumor type were 83.1 and 86.3, respectively. The scores improved in 11 (31.4\%) of the 35 patients and remained stable in 24 (68.6\%).

The mean preoperative and postoperative KPS scores for patients with the prechiastmatic tumor type were 82.6 and 84.2 , respectively. The scores improved in $3(15.7 \%)$ of the 19 patients and remained stable in 16 (84.2\%).

Among the 12 patients with the intra-third ventricle type of tumor, the mean preoperative KPS score was 82.5 and the mean postoperative score was 85.8 . The scores improved in 4 (33.3\%) of the patients and remained stable in $8(66.7 \%)$.

Among the 6 patients with the intrasellar tumor type, the mean preoperative and postoperative KPS scores were
86.7 and 90.0, respectively. The scores improved in 2 patients (33.3\%) and remained stable in 4 (66.7\%).

\section{Pathology}

Twelve patients (16.6\%), all adults, showed a papillary type of craniopharyngioma. Among these 12 patients, 8 had the retrochiasmatic tumor type, 2 the prechiasmatic type, and 2 the intra-third ventricle type.

Sixty patients (83.4\%), consisting of 18 children and 42 adults, showed an adamantinomatous type of craniopharyngioma. Twenty-seven of these patients had the retrochiasmatic tumor type, 17 the prechiasmatic type, 10 the intra-third ventricle type, and 6 the intrasellar type.

\section{Tumor Recurrence}

During the follow-up period, tumor recurrence or regrowth occurred in 15 (20.8\%) of the 72 cases, which included the 32 recurrent cases (Table 2). Tumor recurred in $4(9.3 \%)$ of the 43 patients who had undergone GTR, 10 (35.7\%) of 28 patients who had undergone NTR, and the 1 patient (100\%) who had undergone PR.

For the retrochiasmatic type of tumors, tumor recurrence or regrowth was found in $7(20.0 \%)$ of the 35 patients. Tumor recurrence was noted in $2(10 \%)$ of the 20 patients with GTR, whereas regrowth was detected in 5 (33.3\%) of the 15 patients with NTR.

For the prechiasmatic type of tumors, tumor recurrence or regrowth was found in $6(31.6 \%)$ of the 19 patients. Tumor recurred in 2 (16.7\%) of 12 patients with GTR. Regrowth was detected in $3(50.0 \%)$ of 6 patients with NTR and in the 1 patient (100\%) with PR.

For the intra-third ventricle type of tumors, none of the 12 patients who had undergone GTR (9 patients) or NTR (3 patients) exhibited any tumor recurrence or regrowth.

For the intrasellar type of tumors, tumor recurrence or regrowth was noted in 2 (33.3\%) of the 6 patients. While there was no tumor recurrence in the 2 patients who had

TABLE 2. Surgical outcomes in each group according to an anatomical subclassification of craniopharyngiomas

\begin{tabular}{lcrlll}
\hline \multicolumn{1}{c}{ Group } & $\begin{array}{c}\text { No. of } \\
\text { Patients }\end{array}$ & $\begin{array}{c}\text { Multistage } \\
\text { Surgery }\end{array}$ & \multicolumn{1}{c}{ Approach (no. of cases) } & $\begin{array}{c}\text { Resection } \\
\text { (no. of cases) }\end{array}$ & $\begin{array}{c}\text { Recurrence } \\
\text { (no. of cases) }\end{array}$ \\
\hline All patients & 72 & $26(36.1 \%)$ & OZ 41, IH 21, TP 21, TSS 14, other 3 & GTR 43, NTR 28, PR 1 & 15 (20.8\%) \\
\hline Intrasellar type & 6 & $1(16.7 \%)$ & TSS 6, OZ 1 & GTR 2, NTR 4 & $2(33.3 \%)$ \\
\hline Prechiasmatic type & 19 & $3(15.8 \%)$ & OZ 11, TSS 7, IH 4 & GTR 12, NTR 6, PR 1 & 6 (31.6\%) \\
\hline Retrochiasmatic type & 35 & $15(42.8 \%)$ & OZ 22, TP 21, IH 5, TSS 1, other 3 & GTR 20, NTR 15 & $7(20.0 \%)$ \\
\hline Intra-third ventricle type & 12 & $7(58.3 \%)$ & IH 12, OZ 7 & GTR 9, NTR 3 & $0(0 \%)$ \\
\hline
\end{tabular}

$\mathrm{IH}=$ interhemispheric; other = approaches other than the IH, OZ, TP, or TSS; OZ = orbitozygomatic; TP = transpetrosal; $T S S=$ transsphenoidal. 
TABLE 3. Preoperative and postoperative statuses in 72 patients with craniopharyngioma

\begin{tabular}{|c|c|c|c|c|c|c|c|c|c|c|c|c|}
\hline \multirow[b]{3}{*}{ Group } & \multirow{2}{*}{\multicolumn{2}{|c|}{$\begin{array}{l}\text { Mean VIS } \\
\text { Score }\end{array}$}} & \multicolumn{4}{|c|}{ Endocrinological Dysfunction } & \multirow{2}{*}{\multicolumn{2}{|c|}{ Obesity }} & \multirow{2}{*}{\multicolumn{2}{|c|}{$\begin{array}{c}\text { Neuropsychological } \\
\text { Deficit }\end{array}$}} & \multirow{2}{*}{\multicolumn{2}{|c|}{$\begin{array}{c}\text { Mean KPS } \\
\text { Score }\end{array}$}} \\
\hline & & & \multicolumn{2}{|c|}{$\begin{array}{c}\text { Anterior Pituitary } \\
\text { Hormone }\end{array}$} & \multicolumn{2}{|c|}{$\begin{array}{l}\text { Diabetes } \\
\text { Insipidus }\end{array}$} & & & & & & \\
\hline & Preop & Postop & Preop & Postop & Preop & Postop & Preop & Postop & Preop & Postop & Preop & Postop \\
\hline All patients & 28.7 & 21.8 & $49(68.1 \%)$ & $64(88.9 \%)$ & $25(34.7 \%)$ & $52(72.2 \%)$ & $10(13.9 \%)$ & $19(26.4 \%)$ & $12(16.7 \%)$ & $10(13.9 \%)$ & 83.2 & 86.0 \\
\hline $\begin{array}{l}\text { Intrasellar } \\
\text { type }\end{array}$ & 29.0 & 19.0 & $4(66.7 \%)$ & $5(83.3 \%)$ & $3(50.0 \%)$ & $3(50.0 \%)$ & $0(0 \%)$ & $0(0 \%)$ & $1(14.3 \%)$ & $1(14.3 \%)$ & 86.7 & 90.0 \\
\hline $\begin{array}{c}\text { Prechias- } \\
\text { matic } \\
\text { type }\end{array}$ & 32.7 & 29.9 & $14(73.7 \%)$ & $16(84.2 \%)$ & $7(36.8 \%)$ & $10(52.6 \%)$ & $2(10.5 \%)$ & $5(26.3 \%)$ & $1(5.3 \%)$ & $1(5.3 \%)$ & 82.6 & 84.2 \\
\hline $\begin{array}{l}\text { Retrochi- } \\
\text { asmatic } \\
\text { type }\end{array}$ & 28.7 & 19.9 & $24(68.6 \%)$ & $31(88.6 \%)$ & $15(42.8 \%)$ & $29(82.9 \%)$ & $7(20.0 \%)$ & $11(31.4 \%)$ & $7(20.0 \%)$ & $5(14.3 \%)$ & 83.1 & 86.3 \\
\hline $\begin{array}{c}\text { Intra-third } \\
\text { ventricle } \\
\text { type }\end{array}$ & 21.4 & 14.6 & $7(58.3 \%)$ & $12(100 \%)$ & $0(0 \%)$ & $12(100 \%)$ & $1(8.3 \%)$ & $3(25.0 \%)$ & $3(25.0 \%)$ & $3(25.0 \%)$ & 82.5 & 85.8 \\
\hline
\end{tabular}

Values expressed as number (\% total) or as score.

undergone GTR, regrowth was detected in $2(50 \%)$ of the 4 NTR patients.

Table 4 shows the relationship between local control, extent of tumor removal, and MIB-1 labeling index. The mean MIB-1 index for tumors that recurred was $6.19 \%$ $\pm 4.68 \%$. On the other hand, the mean MIB-1 index for the no-recurrence group was $2.75 \% \pm 2.09 \%$. Our analysis did show a significant relationship between the failure to achieve local control and the MIB-1 labeling index ( $\mathrm{p}<$ 0.05, Mann-Whitney U-test).

In the GTR group, tumor recurred in 4 (9.3\%) of 43 patients, and the mean MIB-1 index in these 4 tumors was $8.88 \% \pm 4.55 \%$. In the no-recurrence/GTR group, the mean MIB-1 index was 3.15\% $\pm 1.99 \%$. Analysis indicated that there was a significant relationship between the failure to achieve local control and the MIB-1 labeling index ( $\mathrm{p}<$ 0.05, Mann-Whitney U-test).

In the NTR group, regrowth was detected in 10 (35.7\%) of the 28 patients. The mean MIB-1 index was 5.52\% \pm $4.56 \%$ for the patients exhibiting regrowth and $1.97 \% \pm$ $2.16 \%$ for the patients with no regrowth. Similar to the findings for the GTR group, there was a significant relationship between the failure to achieve local control and the MIB-1 labeling index for the NTR group $(\mathrm{p}<0.05$, Mann-Whitney U-test).

TABLE 4. Relationship among local control, extent of tumor removal, and MIB-1 labeling index

\begin{tabular}{lcc}
\hline \multirow{2}{*}{$\begin{array}{c}\text { Group } \\
\text { (no. of cases) }\end{array}$} & $\begin{array}{c}\text { No Recurrence } \\
\text { (no. of cases) }\end{array}$ & $\begin{array}{c}\text { Local Recurrence } \\
\text { (no. of cases) }\end{array}$ \\
\hline All cases (72) & $2.75 \pm 2.09(57)$ & $6.19 \pm 4.68(15)^{*}$ \\
\hline GTR (43) & $3.15 \pm 1.99(39)$ & $8.88 \pm 4.55(4)^{*}$ \\
\hline NTR (28) & $1.97 \pm 2.16(18)$ & $5.52 \pm 4.56(10)^{*}$ \\
\hline PR (1) & - & $1.4(1)$
\end{tabular}

Values expressed as mean \pm standard deviation percentage.

* Statistically significant $(p<0.05$, Mann-Whitney U-test).
Regrowth was also detected in the 1 patient $(100 \%)$ with PR. The MIB-1 index in this patient was $1.4 \%$.

Three of the 12 cases of papillary type craniopharyngioma showed tumor recurrence, and 12 of the 60 cases of the adamantinomatous type showed recurrence. There was no statistically significant difference between the papillary and adamantinomatous craniopharyngioma type as regards tumor recurrence (Table 5).

The odd ratios from the univariate logistic regression analysis for predicting tumor recurrence are listed in Table 5 . Multiple logistic regression analysis with a stepwise procedure was performed. Extent of resection and MIB-1 labeling index were selected as independent factors associated with local recurrence. These variables and their adjusted ORs are listed in Table 5.

\section{Long-Term Outcome}

Recurrence-free survival time in the 72 patients was calculated using the Kaplan-Meier method (Fig. 9). The Kaplan-Meier method was also used to calculate the recurrence-free survival times in relation to the extent of resection (Fig. 10). Analysis showed a markedly significant difference in recurrence-free survival between the GTR and the NTR or PR groups ( $<<0.05)$.

The recurrence or regrowth in 14 of the 15 patients was successfully controlled after performing additional resections and stereotactic radiosurgery. The 1 patient who refused any additional tumor resection died from the tumor regrowth at 1 year after the additional stereotactic radiosurgery. Since another 2 patients died of unrelated disease, a total of $69(95.8 \%)$ of the 72 cases, including the 32 recurrent cases, were well controlled at the last follow-up.

\section{Discussion}

\section{Role of Anatomical Subclassification of Craniopharyngiomas}

Craniopharyngiomas are epithelial tumors that are presumed to arise from remnants of Rathke's pouch. Because 
TABLE 5. Potential predictive variables for local recurrence using logistic regression analysis

\begin{tabular}{|c|c|c|c|c|}
\hline \multirow[b]{2}{*}{ Variable } & \multicolumn{2}{|c|}{ Univariate Analysis } & \multicolumn{2}{|c|}{ Multivariate Analysis* } \\
\hline & Crude OR $(95 \% \mathrm{Cl})$ & p Value & Adjusted OR (95\% Cl) & p Value \\
\hline Patient age & $1.00(0.95-1.05)$ & 0.975 & & \\
\hline Male sex & $1.98(0.38-12.46)$ & 0.420 & & \\
\hline Tumor diameter & $1.04(0.97-1.11)$ & 0.257 & & \\
\hline NTR (vs GTR) & $10.16(1.59-101.76)$ & 0.013 & $3.69(1.67-10.06)$ & $<0.001$ \\
\hline MIB-1 labeling index & $1.48(1.17-1.99)$ & 0.003 & $1.46(1.16-1.99)$ & $<0.001$ \\
\hline Adamantinomatous (vs papillary) & $1.73(0.18-13.93)$ & 0.615 & & \\
\hline
\end{tabular}

* Mutivariate analysis after stepwise procedure.

these tumors can occur from any part of the primitive craniopharyngeal duct, the relationship between tumor and surrounding structures, such as the optic chiasm, hypothalamus, anterior communicating artery, and pituitary gland, differs on a case-by-case basis. Therefore, the best way of determining the optimal surgical procedure, rather than sticking to one approach, would be to base the surgery on the specific tumor origin. Thus, we applied a craniopharyngioma classification that specifically took into account the best surgical approach.

\section{Criteria for Selecting Surgical Approaches Based on an Anatomical Subclassification}

Selecting surgical approaches for craniopharyngioma with complicated conditions remains controversial because of the lesion's anatomical location and proximity to critical neurovascular structures. Table 6 lists the surgical approaches utilized in previous large series. ${ }^{4,6,8,10,21,24,25}$

We created a lesion classification that could be used to determine the most appropriate surgical approach. Lesion identification and the approach used during the resections were as follows.

For the intrasellar type of craniopharyngioma, the anatomical relationship of the tumor and the surrounding structure is similar to that seen for a pituitary adenoma. The sellar floor is usually enlarged, and there is no adhe-

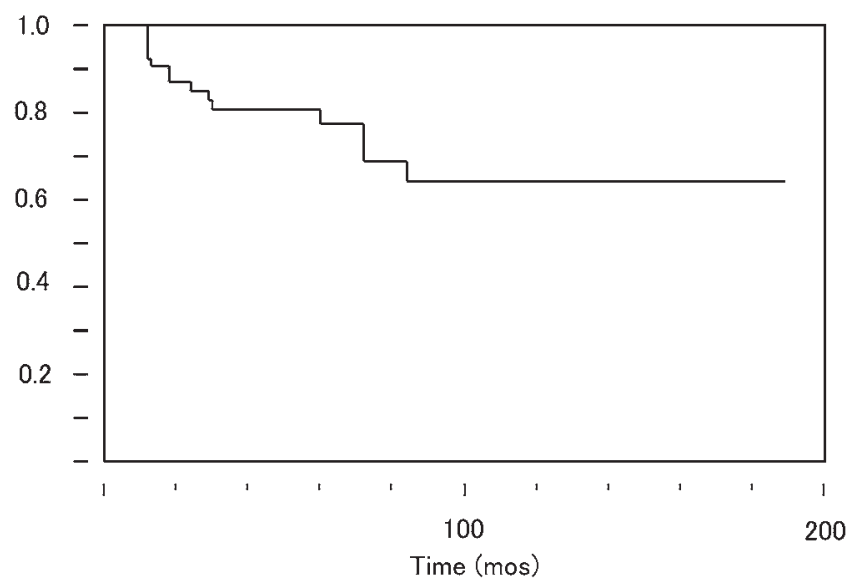

FIG. 9. Recurrence-free survival time was calculated using the KaplanMeier method in all 72 patients. Follow-up times (in months) for the operative periods are shown on the $x$-axis, while recurrence-free survival rates are shown on the $y$-axis. sion with the tumor or with important blood vessels given the fact that the suprasellar side of the tumor is often covered by an extended diaphragm. Therefore, the endoscopic or microscopic transsphenoidal approach is the appropriate procedure for intrasellar type cases (Figs. 2 and 3).

For the prechiasmatic tumor type, the lesion can be reached through a relatively wide space given the elevation of the optic chiasm and the anterior communicating artery. For these types of craniopharyngioma, the use of either the orbitozygomatic or the extended transsphenoidal approach is possible and has been shown to be quite efficient (Fig. 2). When choosing the extended transsphenoidal approach, resection of the tumor is possible because of the large space between the pituitary gland and the optic chiasm as well as the fact that it is easy to directly visualize the posterior and inferior surfaces of the chiasm. However, if the tumor extends extremely to the lateral side, this approach is not suitable (Figs. 2 and 4). When choosing the orbitozygomatic approach, resection of the tumor is relatively easy because there are several corridors that can be used to reach the tumor via the prechiasmatic and opticocarotid spaces, along with the fact that it is easy to observe the underside of the optic chiasm (Figs. 2 and 5).

Although the orbitozygomatic or transpetrosal ap-

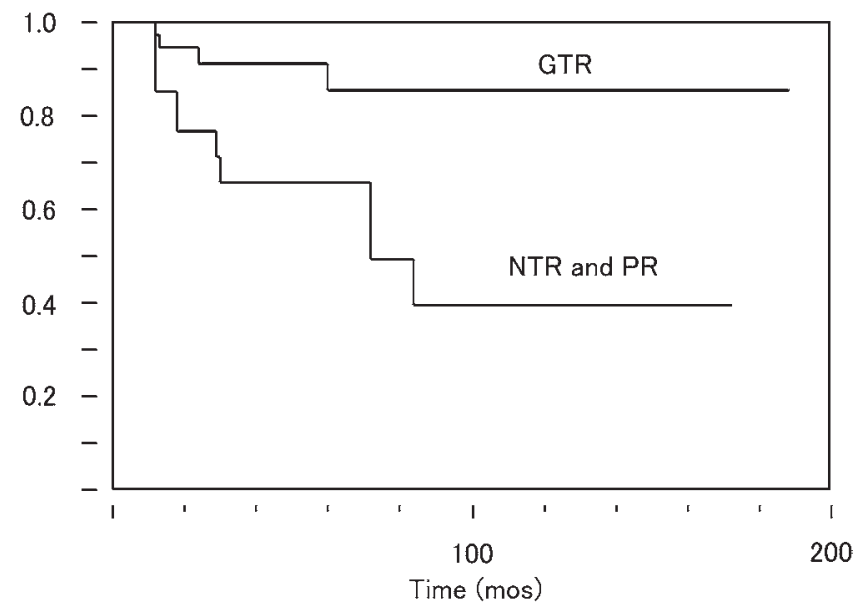

FIG. 10. Kaplan-Meier curves for recurrence-free survival showing comparison of patients with GTR versus patients with NTR and PR $(p<0.05)$. Follow-up times (in months) for the operative periods are shown on the $x$-axis, while recurrence-free survival rates are shown on the $y$-axis. 
TABLE 6. Surgical outcomes of craniopharyngiomas in main series

\begin{tabular}{lccccccc}
\hline \multicolumn{1}{c}{ Authors \& Year } & $\begin{array}{c}\text { No. of } \\
\text { Patients }\end{array}$ & $\begin{array}{c}\% \\
\text { Adults }\end{array}$ & $\begin{array}{c}\text { Surgical } \\
\text { Approach }\end{array}$ & $\begin{array}{c}\text { Aggressive Removal } \\
\text { (GTR or NTR) }\end{array}$ & $\begin{array}{c}\text { Early } \\
\text { Mortality }\end{array}$ & $\begin{array}{c}\text { Mean No. } \\
\text { FU Yrs }\end{array}$ & $\begin{array}{c}\text { Local } \\
\text { Recurrence }\end{array}$ \\
\hline Fahlbusch et al., 1999 & 168 & 80 & Pterional > TSS > IH & $49 \%$ P & $\begin{array}{c}0.7 \% \text { P, } \\
10 \% \text { R }\end{array}$ & 5.4 & $11 \%$ \\
\hline Duff et al., 2000 & 121 & 74 & Pterional > TSS & $43 \%$ & $1.7 \%$ & 10 & $24 \%$ \\
\hline Van Effenterre \& Boch, 2002 & 122 & 76 & Pterional & $59 \%$ & $2.5 \%$ & 4 & $13 \%$ \\
\hline Shi et al., 2008 & 309 & 83.8 & Pterional > IH & $89.3 \%$ & $3.9 \%$ & 2.1 & $17 \%$ \\
\hline Yamada et al., 2010 & 90 & 71 & TSS & $90 \%$ P, 50\% R & $2.2 \%$ & 4.6 & $7.8 \%$ \\
\hline Hofmann et al., 2012 & 65 & NA & IH > TSS > FL & $83.1 \%$ & $0 \%$ & 2.1 & $9.3 \%$ \\
\hline Gerganov et al., 2014 & 16 & NA & FL & $100 \%$ P, $66.7 \%$ R & $0 \%$ & NA & NA \\
\hline Present study & 72 & 75 & OZ > IH/TP > TSS & $100 \%$ P, 92.9\% R & $0 \%$ & 4.7 & $20.8 \%$ \\
\hline
\end{tabular}

$\mathrm{FL}=$ frontolateral approach; $\mathrm{FU}=$ follow-up; $\mathrm{NA}=$ not available; $\mathrm{P}=$ primary cases; $\mathrm{R}=$ recurrent cases.

proaches are selected for the retrochiasmatic tumor type, it should be noted that these resections are associated with high rates of surgical mortality, surgical complications, and incomplete resections that lead to a high recurrence rate (Fig. 2). Since the retrochiasmatic craniopharyngiomas are hidden behind the optic chiasm and have upward extension into the third ventricle and downward extension in front of the brainstem, there is unsatisfactory surgical exposure of these tumors. For the small retrochiasmatic tumor type that occurs without extensive calcification, the orbitozygomatic approach is normally selected as there are several corridors that provide access to the tumor via the prechiasmatic, opticocarotid, and retrocarotid spaces (Figs. 2 and 6). The mini-transpetrosal approach is applied for the retrochiasmatic tumor type that exhibits an extensive amount of calcification or a large diameter (>30 mm). We reported satisfactory results using the mini-transpetrosal approach for the removal of retrochiasmatic craniopharyngiomas under complicated conditions. ${ }^{12}$ The surgical approach used in these types of cases has been described in detail elsewhere. ${ }^{12}$ When using the mini-transpetrosal approach, there are unique posterior-to-anterior and inferior-to-superior surgical corridors to the retrochiasmatic area that provide a relatively wide space for all surgical procedures in the retrochiasmatic space. In addition, use of this approach and the wide space that is available make it possible to directly visualize the posterior and inferior surfaces of the chiasm, the floor of the third ventricle, and the hypothalamic tuber cinereum area. Moreover, use of this posteroanterior corridor to the chiasm and the third ventricle is advantageous as it preserves the small perforating vessels that come from the internal carotid arteries and provide the primary blood supply to the optic chiasm and hypothalamus (Figs. 2 and 7).

For the intra-third ventricle tumor type, the interhemispheric translamina terminalis approach is often used as a way of providing a suitable surgical corridor. With this approach, there is no space around the prechiasmatic area, and there is a narrow working space for tumor resection. This is necessary to preserve the small perforating vessels from the anterior communicating artery or the $A_{1}$ segment that provides blood supply to the hypothalamus. However, if the tumor extends to the inferior side of the optic chiasm and the anterior communicating artery complex, multistage surgery will need to be performed (Figs. 2 and 8).

\section{Surgical Outcomes of Craniopharyngiomas}

Table 6 lists the surgical outcomes of previous large series. ${ }^{4,6,8,10,21,24,25}$ The craniopharyngioma radical resection rates have been found to be $40 \%-90 \%$, with a retrochiasmatic location, larger size, calcification $>10 \%$, extension into the third ventricle, and recurrence reported to be significant prognostic factors that negatively affect the extent of resection..$^{8,12}$ Several studies have reported that the rate of radical resection in repeat surgeries is markedly lower than that in primary surgeries and that there is increased perioperative morbidity and mortality for the repeat surgery cases. ${ }^{6}, 25$ In the present study, 32 patients $(44.4 \%)$ had undergone previous surgical procedures at other institutions, and 35 (48.6\%) of the 72 tumors were classified as the retrochiasmatic type. When using the various approaches based on our anatomical subclassification, we found that GTR or NTR was achieved in $40(100 \%)$ of the 40 primary cases and in 31 (96.9\%) of the 32 recurrent cases.

Hypothalamic damage has been reported to be the most serious complication after these surgeries. ${ }^{6,27}$ Several studies have reported postsurgical hypothalamic damage rates ranging from $65 \%$ to $80 \%, 5,20$ while increases in body weight or obesity range from $39 \%$ to $55 \%$ during long follow-ups. ${ }^{1,14,19,23}$ Hofmann et al.$^{10}$ reported the results of craniopharyngioma treatment in 73 patients, stating that preoperative hypothalamic functional disturbances are considered contraindications for aggressive surgery. In the present study we found that $12(16.7 \%)$ of the 72 patients exhibited neuropsychological deficits before the surgery and that the neuropsychological status was preserved in most patients, although it would be preferable to describe a more robust functional outcome scale. Ten $(13.9 \%)$ of the 72 patients were obese before surgery, and the rate of obesity increased during the follow-up (19 patients [26.4\%]). We also showed that patients with the intra-third ventricle tumor type or the retrochiasmatic type with extension into the third ventricle tended to exhibit neuropsychological deficit or obesity. Therefore, prior to performing surgery, especially in cases with the intra-third ventricle type or 
TABLE 7. Relationship between tumor recurrence and extent of resection in large series

\begin{tabular}{|c|c|c|c|c|c|}
\hline \multirow[b]{2}{*}{ Authors \& Year } & \multirow{2}{*}{$\begin{array}{c}\text { No. of } \\
\text { Patients }\end{array}$} & \multirow{2}{*}{$\begin{array}{l}\text { Mean } \\
\text { FU Yrs }\end{array}$} & \multicolumn{3}{|c|}{ Recurrence (no./total [\% total]) } \\
\hline & & & GTR & NTR or STR & NTR or STR \& RT or SRS \\
\hline Duff et al., 2000 & 121 & 10 & $12 / 66(18 \%)$ & $15 / 30(50 \%)$ & $2 / 22(9 \%)$ \\
\hline Karavitaki et al., 2005 & 121 & 8.6 & $0 / 16(0 \%)$ & $31 / 51(61 \%)$ & $8 / 33(24 \%)$ \\
\hline Mortini et al., 2011 & 106 & 6.9 & $11 / 80(14 \%)$ & $14 / 26(54 \%)$ & NA \\
\hline Lee et al., 2012 & 90 & 5.8 & $20 / 61(33 \%)$ & $11 / 15(73 \%)$ & $5 / 10(50 \%)$ \\
\hline Present study & 72 & 4.7 & $4 / 43(9.3 \%)$ & $6 / 22(27.3 \%)$ & $4 / 6(66.7 \%)$ \\
\hline
\end{tabular}

$\mathrm{RT}=$ radiation therapy; $\mathrm{SRS}$ = stereotactic radiosurgery

the retrochiasmatic type with extension into the third ventricle, it is important to choose the appropriate surgical approach to avoid complications. In some cases it may even be necessary to consider using multistage surgery to avoid potential complications.

In this study, 32 patients (44.4\%) had previously undergone surgical procedures at other institutions, and 35 $(48.6 \%)$ of the 72 tumors were classified as the retrochiasmatic type of craniopharyngioma. We performed aggressive tumor resection even if patients had hypothalamic functional disturbances preoperatively. And we used approaches such as the transpetrosal or orbitozygomatic, which enabled access to the hypothalamus and optic pathway during tumor removal. Our results, as compared with those in other reports, were satisfactory as regards the extent of tumor resection, tumor control, surgical complications, visual function, endocrinological status, neuropsychological function, and functional performance status. ${ }^{1,2,5,8-10,16,19-21,27}$

\section{Long-Term Tumor Control}

Several studies have demonstrated that incomplete resection of craniopharyngiomas results in higher recurrence rates. ${ }^{4,15,18,21,24}$ Duff et al. reported 10-year recurrence-free survival rates of $82 \%$ after GTR and $50 \%$ after subtotal resection (STR). ${ }^{4}$ Karavitaki et al. reported 10 -year recurrence-free survival rates of $100 \%$ after GTR plus radiotherapy and 38\% after STR. ${ }^{11}$ Table 7 shows the relationship between tumor recurrence and extent of resection in large series. ${ }^{4,11,13,17}$

The results of several previous studies have led to a widely supported belief that, to reduce the risks of surgery, craniopharyngiomas with complicated conditions must be treated conservatively with a combination of safe PR and stereotactic radiosurgery. ${ }^{3,22,28}$ In fact, the use of this type of conservative treatment has been reported to lead to acceptable results for some types of craniopharyngiomas. Karavitaki et al. reported a 10-year recurrence-free survival rate of $77 \%$ after a combination of STR and radiation therapy ${ }^{11}$ Duff et al. reported a recurrence rate of only $9 \%$ after STR with radiation therapy. ${ }^{4}$ On the other hand, several studies have reported no significant difference in tumor control between patients who underwent GTR and those who underwent STR with radiation therapy. ${ }^{22,26}$ In the present study, extent of tumor resection and MIB-1 labeling index were identified as independent factors associated with local recurrence (Table 5). Our results, even including the 32 recurrent cases, were similar to outcomes in the studies that did not find any significant differences (Table 7).,11,13,17 Therefore, we believe aggressive resections performed using surgical approaches based on an anatomical subclassification would be the best therapeutic option for craniopharyngiomas, even in cases exhibiting complicated conditions.

\section{Conclusions}

In the present study we examined the surgical outcomes achieved when using an anatomical classification of craniopharyngiomas that was based on tumor origin. Our results demonstrated the benefits of treating craniopharyngiomas via aggressive tumor resection, with the determination of the correct surgical approach essential in achieving a successful outcome.

\section{References}

1. Caldarelli M, Massimi L, Tamburrini G, Cappa M, Di Rocco $\mathrm{C}$ : Long-term results of the surgical treatment of craniopharyngioma: the experience at the Policlinico Gemelli, Catholic University, Rome. Childs Nerv Syst 21:747-757, 2005

2. Chakrabarti I, Amar AP, Couldwell W, Weiss MH: Longterm neurological, visual, and endocrine outcomes following transnasal resection of craniopharyngioma. J Neurosurg 102:650-657, 2005

3. Chiou SM, Lunsford LD, Niranjan A, Kondziolka D, Flickinger JC: Stereotactic radiosurgery of residual or recurrent craniopharyngioma, after surgery, with or without radiation therapy. Neuro Oncol 3:159-166, 2001

4. Duff J, Meyer FB, Ilstrup DM, Laws ER Jr, Schleck CD, Scheithauer BW: Long-term outcomes for surgically resected craniopharyngiomas. Neurosurgery 46:291-305, 2000

5. Elliott RE, Jane JA Jr, Wisoff JH: Surgical management of craniopharyngiomas in children: meta-analysis and comparison of transcranial and transsphenoidal approaches. Neurosurgery 69:630-643, 2011

6. Fahlbusch R, Honegger J, Paulus W, Huk W, Buchfelder M: Surgical treatment of craniopharyngiomas: experience with 168 patients. J Neurosurg 90:237-250, 1999

7. Fahlbusch R, Schott W: Pterional surgery of meningiomas of the tuberculum sellae and planum sphenoidale: surgical results with special consideration of ophthalmological and endocrinological outcomes. J Neurosurg 96:235-243, 2002

8. Gerganov V, Metwali H, Samii A, Fahlbusch R, Samii M: Microsurgical resection of extensive craniopharyngiomas using a frontolateral approach: operative technique and outcome. J Neurosurg 120:559-570, 2014

9. Hoffman HJ, De Silva M, Humphreys RP, Drake JM, Smith ML, Blaser SI: Aggressive surgical management of craniopharyngiomas in children. J Neurosurg 76:47-52, 1992 
10. Hofmann BM, Höllig A, Strauss C, Buslei R, Buchfelder M, Fahlbusch R: Results after treatment of craniopharyngiomas: further experiences with 73 patients since 1997. J Neurosurg 116:373-384, 2012

11. Karavitaki N, Brufani C, Warner JT, Adams CBT, Richards $\mathrm{P}$, Ansorge $\mathrm{O}$, et al: Craniopharyngiomas in children and adults: systematic analysis of 121 cases with long-term follow-up. Clin Endocrinol (Oxf) 62:397-409, 2005

12. Kunihiro N, Goto T, Ishibashi K, Ohata K: Surgical outcomes of the minimum anterior and posterior combined transpetrosal approach for resection of retrochiasmatic craniopharyngiomas with complicated conditions. J Neurosurg 120:1-11, 2014

13. Lee MH, Kim SH, Seoul HJ, Nam DH, Lee JI, Park K, et al: Impact of maximal safe resection on the clinical outcome of adults with craniopharyngiomas. J Clin Neurosci 19:10051008,2012

14. Leng LZ, Greenfield JP, Souweidane MM, Anand VK, Schwartz TH: Endoscopic, endonasal resection of craniopharyngiomas: analysis of outcome including extent of resection, cerebrospinal fluid leak, return to preoperative productivity, and body mass index. Neurosurgery 70:110-124, 2012

15. Maira G, Anile C, Albanese A, Cabezas D, Pardi F, Vignati A: The role of transsphenoidal surgery in the treatment of craniopharyngiomas. J Neurosurg 100:445-451, 2004

16. Merchant TE, Kiehna EN, Sanford RA, Mulhern RK, Thompson SJ, Wilson MW, et al: Craniopharyngioma: the St. Jude Children's Research Hospital experience 1984-2001. Int J Radiat Oncol Biol Phys 53:533-542, 2002

17. Mortini P, Losa M, Pozzobon G, Barzaghi R, Riva M, Acerno $S$, et al: Neurosurgical treatment of craniopharyngioma in adults and children: early and long-term results in a large case series. J Neurosurg 114:1350-1359, 2011

18. Müller HL: Childhood craniopharyngioma. Pituitary 16:5667,2013

19. Müller HL, Emser A, Faldum A, Bruhnken G, Etavard-Gorris N, Gebhardt U, et al: Longitudinal study on growth and body mass index before and after diagnosis of childhood craniopharyngioma. J Clin Endocrinol Metab 89:3298-3305, 2004

20. Poretti A, Grotzer MA, Ribi K, Schönle E, Boltshauser E: Outcome of craniopharyngioma in children: long-term complications and quality of life. Dev Med Child Neurol 46:220-229, 2004

21. Shi XE, Wu B, Fan T, Zhou ZQ, Zhang YL: Craniopharyngioma: surgical experience of 309 cases in China. Clin Neurol Neurosurg 110:151-159, 2008

22. Smee RI, Williams JR, Kwok B, Teo C, Stening W: Modern radiotherapy approaches in the management of craniopharyngiomas. J Clin Neurosci 18:613-617, 2011

23. Srinivasan S, Ogle GD, Garnett SP, Briody JN, Lee JW, Cowell CT: Features of the metabolic syndrome after childhood craniopharyngioma. J Clin Endocrinol Metab 89:81-86, 2004

24. Van Effenterre R, Boch AL: Craniopharyngioma in adults and children: a study of 122 surgical cases. J Neurosurg 97:3-11, 2002

25. Yamada S, Fukuhara N, Oyama K, Takeshita A, Takeuchi Y, Ito J, et al: Surgical outcome in 90 patients with craniopharyngioma: an evaluation of transsphenoidal surgery. World Neurosurg 74:320-330, 2010

26. Yang I, Sughrue ME, Rutkowski MJ, Kaur R, Ivan ME, Aranda D, et al: Craniopharyngioma: a comparison of tumor control with various treatment strategies. Neurosurg Focus 28(4):E5, 2010

27. Yaşargil MG, Curcic M, Kis M, Siegenthaler G, Teddy PJ, Roth P: Total removal of craniopharyngiomas. Approaches and long-term results in 144 patients. J Neurosurg 73:3-11, 1990

28. Zygourakis CC, Kaur G, Kunwar S, McDermott MW, Madden M, Oh T, et al: Modern treatment of 84 newly diagnosed craniopharyngiomas. J Clin Neurosci 21:1558-1566, 2014

\section{Disclosures}

No funds were received in support of this work. No benefits in any form have been or will be received from a commercial party related directly or indirectly to the subject of this manuscript.

\section{Author Contributions}

Conception and design: Morisako, T Goto. Acquisition of data: Morisako. Analysis and interpretation of data: Morisako, H Goto. Drafting the article: Morisako. Critically revising the article: Morisako, T Goto. Reviewed submitted version of manuscript: Morisako, T Goto, H Goto, Bohoun, Tamrakar. Approved the final version of the manuscript on behalf of all authors: Morisako. Statistical analysis: Morisako. Administrative/technical/material support: T Goto, H Goto, Ohata. Study supervision: T Goto, H Goto, Ohata.

\section{Correspondence}

Hiroki Morisako, Department of Neurosurgery, Osaka City University Graduate School of Medicine, 1-4-3 Asahi-machi, Abeno-ku, Osaka 545-8585, Japan. email: hmorisako@med. osaka-cu.ac.jp. 